\title{
White Bread
}

\author{
Piet Defraeye \\ University of Alberta, Canada
}

There's probably no other art form that depends and engages as thoroughly with memory as theatre performance. Its sequential nature itself is an exercise of physical and discursive memory, for the performers as well as the audience. Acting itself has often been theorized, most famously by Konstantin Stanislavsky, as memory put into physical practice. A recent production that plays and interacts with memory of popular cultural discourse is a good example. White Bread toured in five European cities in four countries in 2014 and tapped into different reservoirs of memory for its local reception. However, the production too was the result of how playwright, actress and director engaged with their memory of cultural spectacle, as provided by the cultural icon Madonna and the surrounding world of simulacra and cliché cultural icons like Coca-Cola glass bottles, and the iconic square-shaped white Wonderbread.

Mia Van Leeuwen, a Winnipeg-based performance artist, conceived White Bread during her MFA studies in Theatre Practice at the University of Alberta in 2013 and after she wrote a first draft, we teamed up together with her as author-performer, and myself in the role of dramaturg-director. The performance piece presents the story of Abby, Madonna's British maid, who is a pill-popping bundle of anxiety. She is clearly mesmerized by the grand lifestyle of her employer, and is on a path of destructive imitation of "The Lady of the Fame and Fortune," while at the same time she is able to formulate a good deal of common sense. The text references a collage of sources including Jean Genet's The Maids, Don DeLillo's Cosmopolis, lyrics from songs by Madonna and White Bread: A Social History of the Store-Bought Loaf by Aaron Bobrow-Strain; as well as original text by van Leeuwen, and rehearsal-based improvisation. As we engaged with the text and the imagery it conjured, we found ourselves re-surfacing iconic imagery which acquired a strong sense of semiotics in the show because of its quasi-nostalgic semiotics. Abby ends up drinking coke from a classically shaped coca cola bottle, and relishes sitting under a Coca Cola beach umbrella, which we found in the dusty basement of an Antwerp theatre. It was important, we found out, that this imagery be instantly recognizable through a shared memory function with the audience - yet that it not spur nostalgic feelings, but rather set in motion an ironic tension with what was seen and experienced. Ultimately, the stage provides an interactive field of translating memory - for the makers (writer, actress, director) to translate their memory of popular cultural discourse, for the character (Abby), to translate her (un)coping with the memories of her dedicated life, and for the audience (in various cities) to retranslate the experience developing in front of them on the stage into a recognizable interaction of memory and authentic experience. 


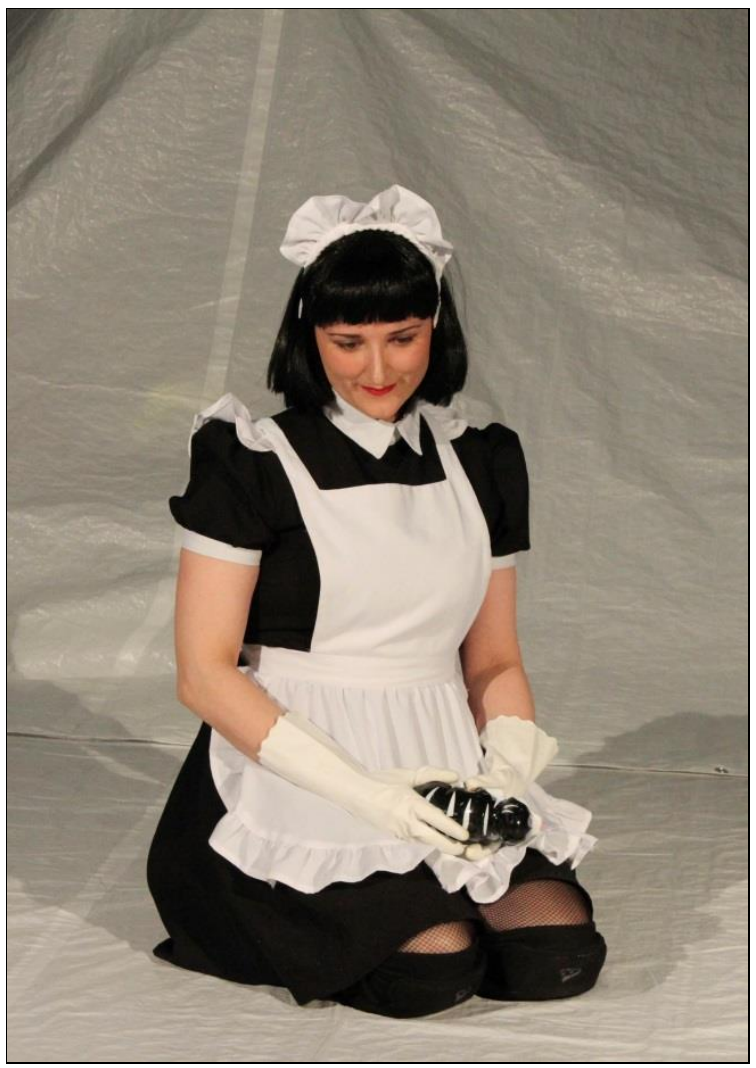

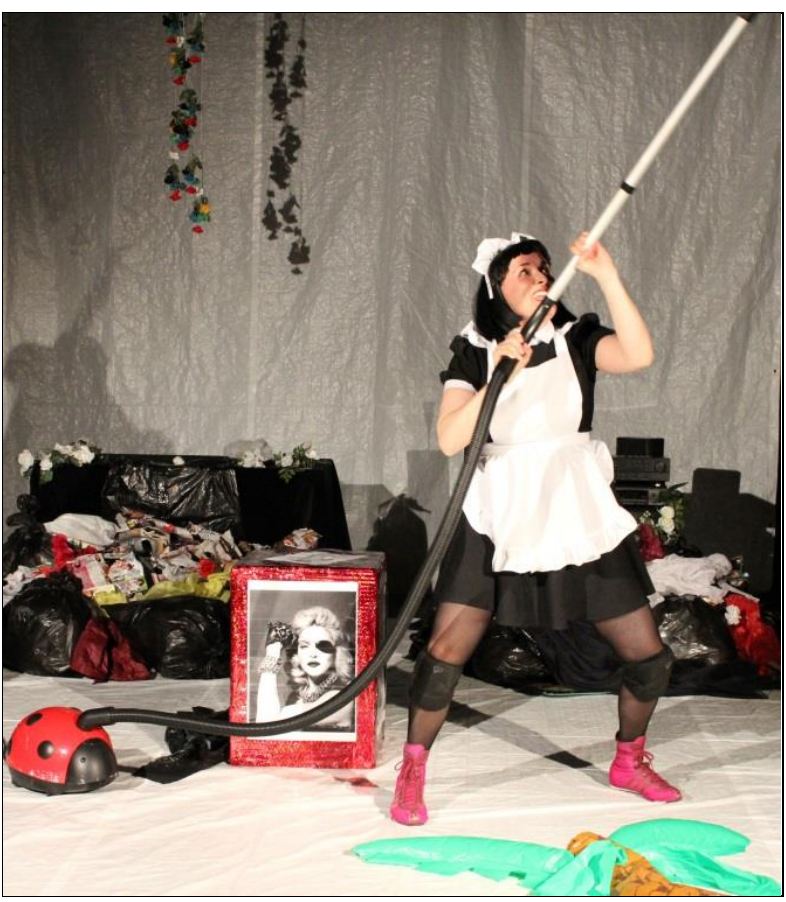

Photo credit: Mia Van Leeuwen/Piet Defraeye

Photo credit: Mia Van Leeuwen/Piet Defraeye

White Bread deals with celebrity and addiction, and provides a critique on capitalism and the questionable idealism of the American Dream, juxtaposed with the aging and waning star power of the pop-icon Madonna. The title references the place of white bread as an iconic cultural symbol in our taxonomy of physical and spiritual nourishment, of which there typically is precious little in the case of white bread. It has always baffled me how popular this industrial white bread is. I have a brotherin-law who has carved out a wholesale business in St. Barthélémy a small town in Quebec, to the East of Montreal, just by setting up and managing early morning delivery rounds of the massproduced bread to convenience stores in the area. You obviously need quite a few pallets of bread for the pennies per loaf so as to make this a viable business, and his certainly is!

For the purpose of the play, we wanted to use the iconic blue-white-red (Classic!) Wonderbread, though after we found out the inflated price of this supposedly cheap processed staple for the masses, we quickly resorted to recycled Wonderbread bags, stuffed with look-alikes. This solution was part of an aesthetics of simulacra, which of course is typical for theatre, but in this case, it was an ironic extension of the basic motif of the piece. However, it also presented some unexpected difficulties on our European tour, and proved particularly challenging in Munich, where they do know what bread is. We did probably about six or seven bakeries in the Schwabing area of Munich, where the Studiobühne is situated, before we found a loaf that was sufficiently square, soft, and white. 


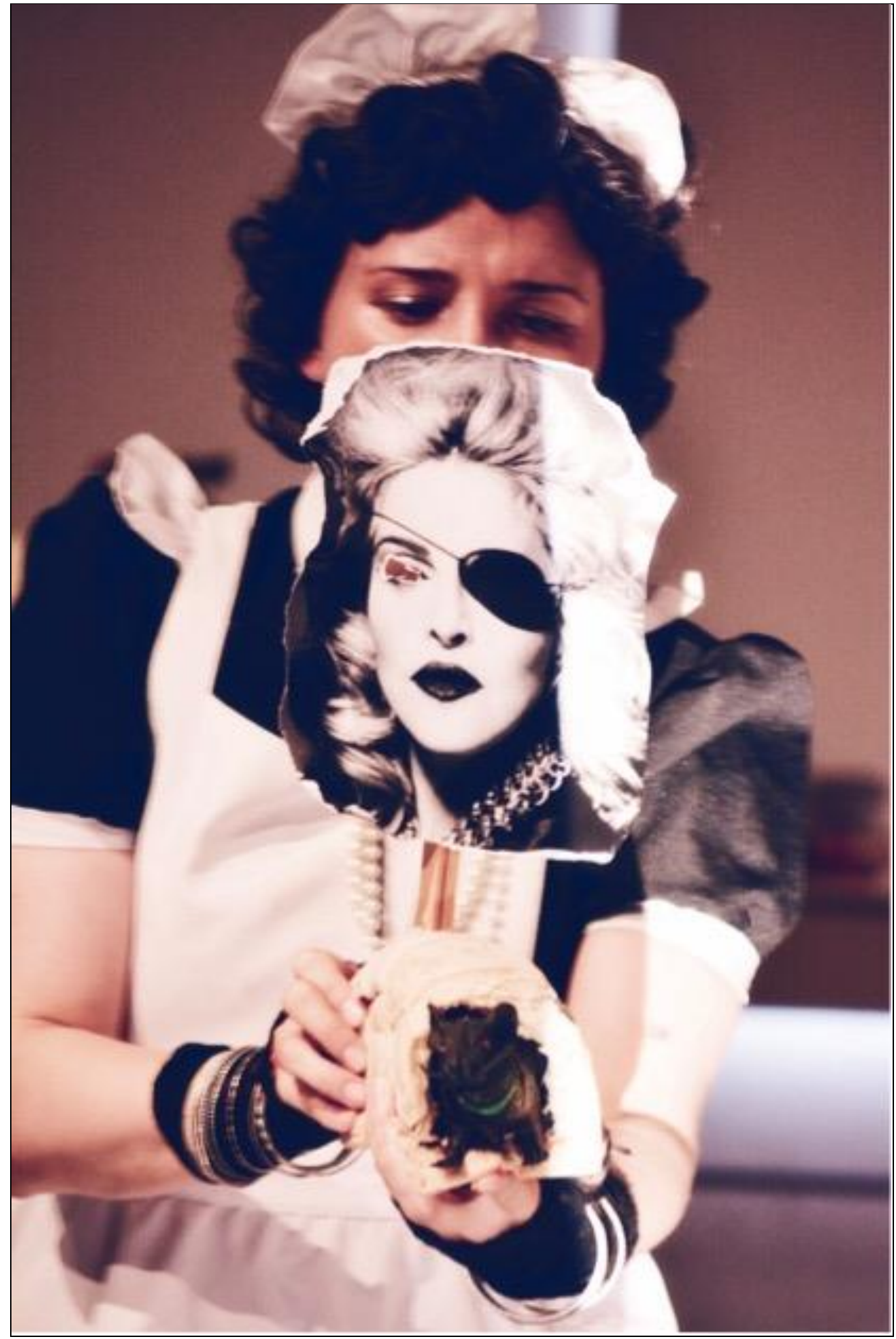

Photo credit: Mia Van Leeuwen/Piet Defraeye

The bread was less of an issue during try-outs in Edmonton, and the (then) American grocery chain Safeway was our favorite supplier, as their square-whites were the right consistency for 
Mia to hollow it out from the inside while keeping the form and outside crust, so the empty loaf functions as a little house for a plastic rat halfway the show.

While the ideas of simulacrum and celebrity are central to the show, Abby's raison d'etre is profoundly based in her participation in consumption. So, during rehearsals in Antwerp, we tried to bring these motifs together and decided to build the effigy of Madonna with recycled materials like plastic bottles and jars, and recycled wrapping paper, stuffed in nylon stockings and corsets, the whole thing adorned with a baffling Madonna look-alike mask, which Mia had purchased years ago. The effigy plays a crucial role in the middle of the play, as a symbol for Madonna's aging body, but also as an image of duplication and simulacrum, as well as the object and catalyst of frustration in Abby's dystopian world of self-destruction.

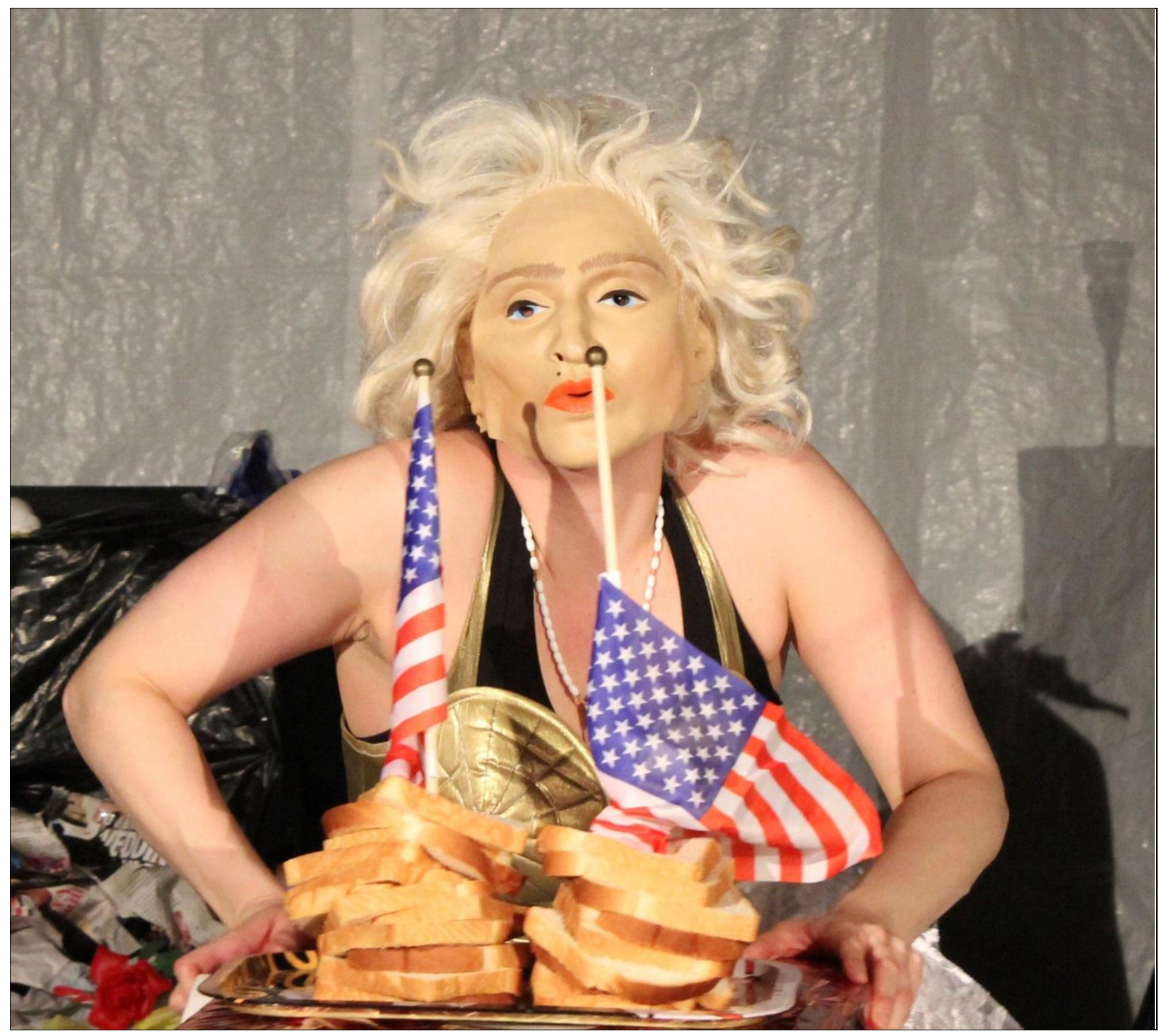

Photo credit: Mia Van Leeuwen/Piet Defraeye 
TranscUlturAl, vol. 8.1 (2016), 101-105.

http://ejournals.library.ualberta.ca/index.php/TC

Our European tour started in Antwerp in June 2014, with the production's world premiere at the Carwash Theatre, the venue of the collective AndWhatBeside(s)Death. On the second night, there was a very good turn-out, and my niece was there, with her husband Alex - whose left side is paralyzed due to a bicycle accident in his late teens, and is therefore in a wheelchair. They were in the front row - and just loved the show and this crazy character Abby! In the play, Abby regularly resorts to her pill-box to pop a capsule so that "everything will be better!" and sometimes offers the audience a pill too — "would you like to try it!?" — emphasizing that "everything will be better!" When Alex spontaneously — and smilingly — extended his (functioning!) right hand for a pill, Abby, for a moment, was quiet - a very rare feet for this character, who constantly babbles on, talking away her own neurosis. It was a beautiful and authentic moment in the show, and afterwards, actress and spectator had a lengthy de-briefing about the emotions and thoughts that went back and forth in those 10 seconds. A treasurable memory! ${ }^{\mathrm{i}}$

${ }^{\mathrm{i}}$ White Bread is also programmed for StageLab Festival in Edmonton, August 25-28, 2016. 